\begin{tabular}{|c|c|}
\hline Title & Hydrogen I sotope A bsorption in U nary Oxides and Nitrides with A nion V acancies and Substitution \\
\hline Author(s) & W atanabe, Takumi; Kunisada, Y uji; Sakaguchi, Norihito \\
\hline Citation & $\begin{array}{l}\text { ChemPhysChem, 20(10), 1369-1375 } \\
\text { https://doi.org/10.1002//phc.201801091 }\end{array}$ \\
\hline Issue Date & 2019-05-16 \\
\hline Doc URL & http:/hdl.handle.net/2115/78014 \\
\hline Rights & $\begin{array}{l}\text { This is the peer reviewed version of the following article: T. W atanabe, Y. Kunisada, N. Sakaguchi, ChemPhysChem } \\
2019,20,1369, \text { which has been published in final form at hittps://doi .org/10.1002/cphc.201801091. This article may be } \\
\text { used for non-commercial purposes in accordance with Wiley Terms and Conditions for U se of Self-A rchived V ersions. }\end{array}$ \\
\hline Type & article (author version) \\
\hline File Information & accepted manuscript(kunisada).pdf \\
\hline
\end{tabular}

Instructions for use 


\title{
Hydrogen isotope absorption in unary oxides and nitrides with anion vacancies and substitution
}

\author{
Takumi Watanabe, ${ }^{[a]}$ Yuji Kunisada, ${ }^{*[a]}$ and Norihito Sakaguchi[ ${ }^{[a]}$
}

\begin{abstract}
The absorption states of hydrogen isotopes in various ceramic materials were investigated by density functional theory. For pristine ceramic materials, main-group oxides do not form any bond with a hydrogen atom. However, transition metal oxides form hydroxyl groups and absorb hydrogen atoms. Main-group and transition metal nitrides form ionic bonds between a hydrogen atom and the surrounded cation. For anion-deficient ceramic materials, hydrogen atoms are negatively charged because of excess electrons induced by anion vacancies, and ionic bonds form with the surrounded cation, which stabilizes the hydrogen absorption state. $\mathrm{N}$ substitutional doping into oxides introduces an electron hole, while $\mathrm{O}$ substitutional doping into the nitrides introduces an excess of electrons. Therefore, hydrogen isotopes form covalent bonds in $\mathrm{N}$ substituted oxides, and form hydride ions in O-substituted nitrides. Thus, $\mathrm{Al}_{2} \mathrm{O}_{3}, \mathrm{SiO}_{2}, \mathrm{CrN}$, and $\mathrm{TiN}$ are promising materials as hydrogen permeation barriers.
\end{abstract}

\section{Introduction}

Environmental concerns caused by fossil fuel consumption have grown in recent years. This is because fossil fuel consumption leads to emissions of carbon dioxide and other greenhouse gases, which is argued to be a major cause of climate change..$^{1]}$ In addition, it has been estimated that the demand for energy is expected to approximately double by $2050 .{ }^{[2]}$ One way of reducing emissions of greenhouse gases is by utilizing fuel cells with hydrogen derived using renewable energy resources. To realize efficient hydrogen storage, hydrogen gas in the storage tanks of the fuel cell vehicle is compressed to $70 \mathrm{MPa}$, and more greatly compressed hydrogen gas is used at the hydrogen station. Metallic materials, in particular hard carbon steels, are degraded by hydrogen embrittlement in high-pressure hydrogen environments. Therefore, it is necessary to adopt materials that can suppress hydrogen embrittlement. Currently, hydrogen storage tanks are manufactured from high-cost materials, such as Eurofer97, SUS316L, SUS321, ${ }^{[3-5]}$ aluminum alloy ${ }^{[6]}$ and carbon composites. ${ }^{[7]}$ Therefore, to make wide use of hydrogen as a new green energy storage medium, there is a need to develop

[a] T. Watanabe, Dr. Y. Kunisada, Dr. N. Sakaguchi Center for Advanced Research of Energy and Materials, Hokkaido University, Kita 13 Nishi 8, Kitaku, Sapporo 060-8628 (Japan) E-mail:kunisada@eng.hokudai.ac.jp

Supporting information for this article is given via a link at the end of the document. long lasting and low-cost hydrogen storage tank materials that can suppress hydrogen embrittlement. Moreover, hightemperature hydrogen isotopes exist as fuels and products in nuclear fusion reactors. ${ }^{[4,8]}$ Therefore, the embrittlement of blanket materials caused by hydrogen isotopes has to be suppressed.

One of the most simple and inexpensive ways to suppress hydrogen embrittlement is by forming ceramic coating layers as hydrogen permeation barriers (HPBs), which reduce hydrogen permeation into the materials. ${ }^{[9]}$ Ceramic coating is easily formed by annealing or deposition in an oxygen and nitrogen atmosphere, which can be carried out without expensive and complicated equipment. ${ }^{[9-14]}$ Some ceramic coating films show reduced hydrogen isotope permeation and it is known that most ceramic materials do not bring on hydrogen embrittlement themselves. The suppression of hydrogen permeation using TiN coating films formed on stainless steel has been reported in the literature. ${ }^{[4,10,11,17]}$ These results indicate that TiN coating films are promising candidates for HPBs. In addition, It has been also reported that hydrogen absorption in $\mathrm{Al}_{2} \mathrm{O}_{3}{ }^{[15]}$ and $\mathrm{TiO}_{2}{ }^{[16]}$ are energetically unfavorable using first-principles calculations. Therefore, we can use inexpensive materials, such as carbon steel, as hydrogen storage tanks with such ceramic coating films. In addition, ceramic materials are very stable, even under high temperature conditions. Thus, they are applicable as blanket materials for nuclear fusion reactors. ${ }^{[8]}$ Atomic vacancies and impurities in ceramic materials also affect their hydrogen permeation properties. For example, atomic vacancies and substitutional impurities act as hydrogen trap sites, which results in enhancement of hydrogen dissolution and concentration. ${ }^{[16,18-}$ 20] In addition, oxygen vacancies also gives the hydrogen conductivity to oxides. ${ }^{[21]}$ From these points, to identify suitable ceramic materials for HPBs it is necessary to clarify the effects of atomic vacancies and substitutional impurities in the ceramics on hydrogen permeation properties.

Herein we investigated the hydrogen absorption properties of a series of inexpensive ceramic materials using first-principles calculations based on density functional theory (DFT) as a first step to reveal hydrogen permeation properties. We focused on the effects of atomic vacancies and anion substitutional impurities on the hydrogen absorption properties.

\section{Computational methods}

First-principles calculations were performed based on spinpolarized DFT to evaluate the absorption properties of hydrogen isotopes using the Vienna ab initio Simulation Package (VASP 
5.4.1) ${ }^{[22-24]}$ with the projector-augmented wave (PAW) ${ }^{[26,27]}$ method. The exchange-correlation functional was represented with the generalized gradient approximation (GGA) proposed by Perdew, Burke, and Ernzerhof (PBE). ${ }^{[28]}$ Ceramic materials of main-group elements ( $\mathrm{Al}$ and $\mathrm{Si})$ and transition metals $(\mathrm{Cr}, \mathrm{Fe}$ and $\mathrm{Ti}$ ) were considered, with both oxides and nitrides of these elements. Table 1 shows the ceramic materials studied in this work. The atomic and crystal structures of these ceramic materials are shown in Figure S1 and Table S1. We note that the symmetry of the systems become lower after hydrogen absorption. In the case of transition metal oxides and nitrides, the conventional GGA-PBE functional was supplemented with the on-site Coulomb interaction $U$ proposed by Dudarev and coworkers ${ }^{[29]}$. The corresponding $U$ values of each ceramic material were obtained from previous studies, ${ }^{[30-37]}$ as shown in Table S2. Table S2 also shows the parameters of the planewave basis cutoff and Brillouin zone sampling with MonkhorstPack grid. ${ }^{[38]}$ These parameters were determined to keep the total energy convergence per one atom to be less than $0.005 \mathrm{eV}$. Gaussian smearing with $\sigma$ of $0.05 \mathrm{eV}$ was adopted. All atoms were relaxed using the conjugate gradient method until the Hellmann-Feynman forces on each atom became less than $0.02 \mathrm{eV} / \AA \AA$. We did not apply any symmetry constraint during structural relaxation.

We considered a single anion vacancy and substitutional impurity in the ceramic materials. The vacancy formation energy, $E_{V}$, of anion $\mathrm{X}(=\mathrm{O}$ or $\mathrm{N})$ can be written as:

$$
E_{V}=E_{\text {bulk }}^{V}+\frac{1}{2} E_{X_{2}}-E_{\text {bulk }}
$$

where $E_{\text {bulk }}$ and $E_{b u l k}^{V}$ are the total energy of ceramic materials without and with a single anion vacancy, respectively, and $E_{X_{2}}$ is the corresponding energy of the isolated diatomic molecule.

The formation energy of a single substitutional oxygen impurity, $E_{S}^{O}$, and a single nitrogen substitutional impurity, $E_{S}^{N}$, can be written as:

$$
\begin{aligned}
& E_{S}^{O}=E_{\text {bulk }}^{S}+\frac{1}{2} E_{N_{2}}-\left(E_{\text {bulk }}+\frac{1}{2} E_{O_{2}}\right), \\
& E_{S}^{N}=E_{\text {bulk }}^{S}+\frac{1}{2} E_{O_{2}}-\left(E_{\text {bulk }}+\frac{1}{2} E_{N_{2}}\right),
\end{aligned}
$$

where $E_{\text {bulk }}^{S}$ is the total energy of the ceramic material with a single anion substitutional impurity.

We considered several highly symmetric inequivalent initial hydrogen absorption sites in each ceramic material to clarify the most stable hydrogen absorption sites, as shown in Figure S1. The absorption energy of the hydrogen atoms in the ceramic materials, $E_{a}$, can be written as:

$$
E_{a}=E_{H / b u l k}^{V, S}-\left(E_{\text {bulk }}^{V, S}+\frac{1}{2} E_{H_{2}}\right)
$$

Where $E_{H / b u l k}^{V, S}$ is the total energy of the ceramic material with an absorbed $\mathrm{H}$ atom. To investigate isotope effects on the absorption energy, we considered the vibrational zero-point energy (ZPE) of the hydrogen isotopes. The vibrational ZPE was calculated using the harmonic oscillator approximation. The calculated ZPE of $\mathrm{H}_{2}, \mathrm{D}_{2}$ and $\mathrm{T}_{2}$ were $0.283,0.200$ and $0.163 \mathrm{eV}$, respectively.

We evaluated the electron transfer based on a Bader charge analysis. ${ }^{[39,40]}$ We used Visualization for Electronic and Structure Analysis (VESTA) to visualize the atomic models and electron density distributions. ${ }^{[41]}$
Table 1. Ceramic materials considered in this work.

\begin{tabular}{ccc}
\hline & Oxides & Nitrides \\
\hline $\mathrm{Al}$ & $\alpha-\mathrm{Al}_{2} \mathrm{O}_{3}$ & w-AIN \\
$\mathrm{Si}$ & $\alpha-\mathrm{SiO}_{2}$ & $\alpha-\mathrm{Si}_{3} \mathrm{~N}_{4}$ \\
$\mathrm{Cr}$ & $\alpha-\mathrm{Cr}_{2} \mathrm{O}_{3}$ & $\mathrm{CrN}, \mathrm{Cr}{ }_{2} \mathrm{~N}$ \\
$\mathrm{Fe}$ & $\alpha-\mathrm{Fe}_{2} \mathrm{O}_{3}, \mathrm{Fe}_{3} \mathrm{O}_{4}$ & $\mathrm{Fe} 2 \mathrm{~N}, \varepsilon-\mathrm{Fe} \mathrm{N}_{3} \mathrm{~N}$ \\
$\mathrm{Ti}$ & $\mathrm{rutile} \mathrm{TiO}_{2}$ & $\mathrm{TiN}$ \\
\hline
\end{tabular}

\section{Results and Discussion}

\section{Hydrogen absorption in pristine ceramic materials}

The calculated hydrogen absorption energies in pristine ceramic materials are shown in Figure 1. The most stable absorption sites of each ceramic material are shown in Figures S2 and S3. We note that the calculated hydrogen absorption energy in pristine $\mathrm{Al}_{2} \mathrm{O}_{3}$ and $\mathrm{TiO}_{2}$ shows good agreement with the previous theoretical reports. ${ }^{[15,16]}$ From Figure 1, we find that the main-group oxides and nitrides show large positive hydrogen absorption energies, which means that hydrogen isotopes cannot absorb in these materials. In contrast, hydrogen isotopes can absorb more favorably in transition metal oxides. In the cases of the transition metal nitrides, $\mathrm{CrN}$ and $\mathrm{TiN}$ show large positive hydrogen absorption energies. These results indicate that $\mathrm{Al}_{2} \mathrm{O}_{3}, \mathrm{SiO}_{2}, \mathrm{AIN}, \mathrm{Si}_{3} \mathrm{~N}_{4}, \mathrm{CrN}$ and $\mathrm{TiN}$ are promising HPB candidates. This result is consistent with a previous study, which reported that $\mathrm{Al}_{2} \mathrm{O}_{3}, \mathrm{TiO}_{2}$, and $\mathrm{TiN}$ show a higher propensity for permeation reduction than does $\mathrm{Cr}_{2} \mathrm{O}_{3}$. ${ }^{[8]}$

Since the hydrogen isotope absorption states depend on whether the cations are main-group or transition metal based, the hydrogen isotope absorption states were compared between $\mathrm{Al}_{2} \mathrm{O}_{3}$ and $\mathrm{Cr}_{2} \mathrm{O}_{3}$. Figure 2(a) shows the electron density distribution of the most stable absorption configuration of $\mathrm{Al}_{2} \mathrm{O}_{3}$. The electron density between $\mathrm{O}-\mathrm{H}$ and $\mathrm{Al}-\mathrm{H}$ is less than $0.2 \mathrm{e} / \AA^{3}$. In addition, only a slight increase in the number of electrons in the vicinity of a hydrogen atom is observed from the differential electron density distribution before versus after hydrogen absorption, as shown in Figure S4. The calculated oxidation number of the hydrogen atom is only -0.148 . Figure $3(a)$ shows the projected density of states (pDOS) of $\mathrm{H}$ and the adjacent $\mathrm{Al}$ and $\mathrm{O}$ atoms in $\mathrm{Al}_{2} \mathrm{O}_{3}$. In Figure $3(\mathrm{a})$, the $\mathrm{H}$ atoms do not have any peaks in common with the other atoms. These results indicate that the hydrogen atom absorbed in $\mathrm{Al}_{2} \mathrm{O}_{3}$ does not make any strong ionic or covalent bonds with the adjacent atoms. This trend is also found in the case of $\mathrm{SiO}_{2}$, as shown in Figure S4. However, the electron density between $\mathrm{O}-\mathrm{H}$ is greater than $0.7 \mathrm{e} / \AA^{3}$, as can be observed for $\mathrm{Cr}_{2} \mathrm{O}_{3}$ from Figure 2(b). Figure $3(\mathrm{~b})$ shows the pDOS of $\mathrm{H}$ and the adjacent $\mathrm{O}$ atoms in $\mathrm{Cr}_{2} \mathrm{O}_{3}$. In Figure $3(\mathrm{~b})$, both the $\mathrm{H}$ and $\mathrm{O}$ atoms have peaks at $-9.5 \mathrm{eV}$, which means that a hydroxyl group is formed. In addition, we can see a clear increase in electron density between the $\mathrm{O}$ and $\mathrm{H}$ atoms in all transition metal oxides, as 


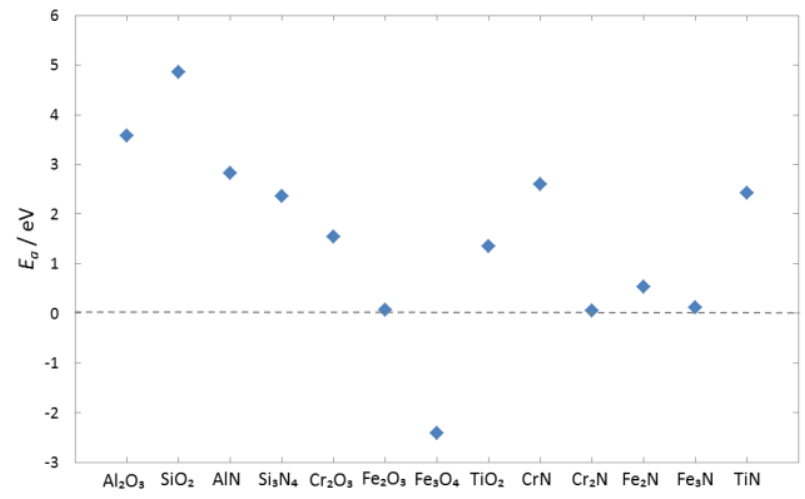

Figure 1. Calculated hydrogen absorption energy, including ZPE, in pristine ceramic materials.
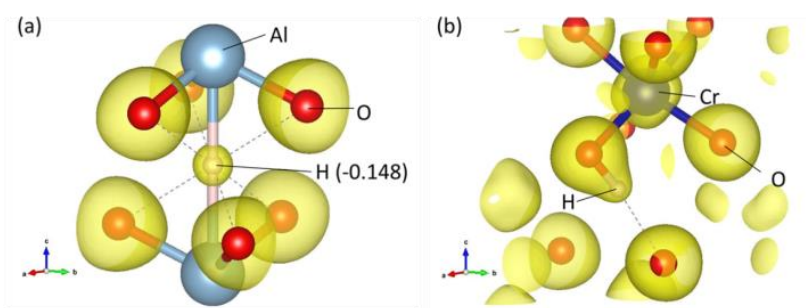

Figure 2. Electron density distribution of the most stable hydrogen absorption configuration of (a) $\mathrm{Al}_{2} \mathrm{O}_{3}$ and (b) $\mathrm{Cr}_{2} \mathrm{O}_{3}$. The isosurface is described at 0.7 $\mathrm{e} / \AA^{3}$.

shown Figure S4. These results indicate that a hydroxyl group can be formed in transition metal oxides. When the hydrogen atom forms a hydroxyl group, the excess electrons are transferred to the cation because of the difference in oxidation numbers between $\mathrm{O}^{2-}$ and $\mathrm{OH}^{-}$. Main-group elements have only a single stable oxidation state; therefore, hydrogen isotopes cannot form a hydroxyl group in main-group oxides. In contrast, a transition metal has several stable oxidation states thanks to its partially occupied $d$ orbital, which results in formation of a hydroxyl group for transition metal oxides.

In the cases of the nitrides, no covalent bonds are evident between the $\mathrm{H}$ and $\mathrm{N}$ atoms in any of the main-group or transition metal nitrides studied. For instance, Figure 4 shows the electron density distribution of the most stable hydrogen absorption configuration of AIN and TiN, where no covalent bond between $\mathrm{H}$ and adjacent atoms is observed. Figure S5 shows the differential electron density distribution for before versus after hydrogen absorption in main-group and transition metal nitrides. From Figure S5, we can see that the hydrogen atoms are negatively charged except for the case of $\mathrm{Si}_{3} \mathrm{~N}_{4}$, because $\mathrm{H}$ atoms are coordinated with $\mathrm{N}^{3}$. Therefore, $\mathrm{H}$ atoms cannot form any bonds with ceramic materials. The oxidation numbers of the hydrogen atoms and the bond length between $\mathrm{H}$ and the corresponding cations in each nitride are shown in Table 2. These values are clearly more negative than those for the hydrogen atoms in the main-group oxides except for the case of $\mathrm{CrN}$. In the case of $\mathrm{CrN}$, we note that $\mathrm{H}$ atoms form covalent bonds with coordinating $\mathrm{N}$ atoms because $\mathrm{Cr}$ atom can change its oxidation number more easily than $\mathrm{Si}$ atoms. We note that the
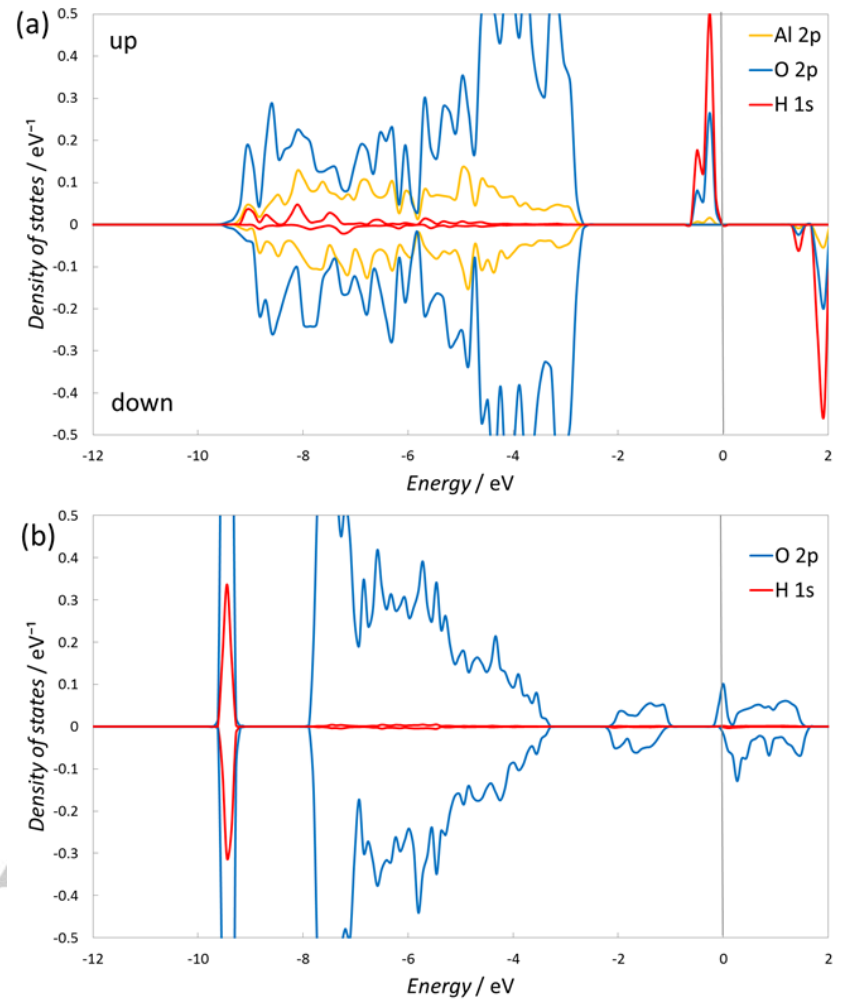

Figure 3. pDOS of a hydrogen atom adsorbed in (a) $\mathrm{Al}_{2} \mathrm{O}_{3}$ and (b) $\mathrm{Cr}_{2} \mathrm{O}_{3}$.
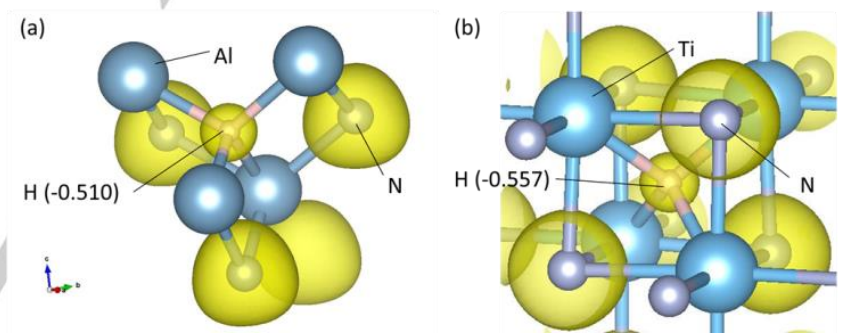

Figure 4. Electron density distribution of the most stable absorption configuration of (a) AIN and (b) TiN. The isosurface is described at $0.7 \mathrm{e} / \AA^{3}$.

electron density in the vicinity of a hydrogen atom also increases in $\mathrm{Fe}_{3} \mathrm{~N}$ (see Figure S5), but the Bader charge analysis cannot calculate the oxidation number accurately. This is because that the distance between $\mathrm{H}$ and $\mathrm{Fe}$ atoms is short. The origin of electron transfer from nitrides to $\mathrm{H}$ atoms is the similar electronegativity of the $\mathrm{H}$ and $\mathrm{N}$ atoms. The electronegativity of the $\mathrm{H}(2.20)$ atoms is closer to that of $\mathrm{N}(3.04)$ than that of $\mathrm{O}$ (3.44). ${ }^{[42]} \mathrm{H}$ atoms can obtain more electrons from nitrides than from oxides. In addition, the bond length between the $\mathrm{H}$ and cations almost corresponds to the ionic radii of each cation and $\mathrm{H}^{-}$. However, from Figure 1, we can find that it is difficult for $\mathrm{H}$ atoms to absorb in not only $\mathrm{Si}_{3} \mathrm{~N}_{4}$ but $\mathrm{AIN}, \mathrm{CrN}$, and TiN. This is because, in AIN, CrN and TiN, there is not enough space for hydrogen absorption. In addition, both the cations and anions coordinate to absorbed $\mathrm{H}$ atoms. 
Table 2. Oxidation number of $H$ atoms, the bond length of $H$ and corresponding atoms, and sum of the corresponding ion radii ${ }^{[43]}$ in pristine ceramic materials.

\begin{tabular}{cccc}
\hline & $\begin{array}{c}\text { Oxidation } \\
\text { number of } \mathbf{H} \\
\text { atoms }\end{array}$ & $\begin{array}{c}\text { Bond length } \\
(\AA)\end{array}$ & $\begin{array}{c}\text { Sum of ion } \\
\text { radii }(\AA)\end{array}$ \\
\hline $\mathbf{A I N}$ & -0.51 & 1.82 & 2.05 \\
$\mathrm{CrN}$ & +0.30 & $1.32(\mathrm{~N}-\mathrm{H})$ & $1.07(\mathrm{~N}-\mathrm{H})$ \\
$\mathrm{Cr}_{2} \mathrm{~N}$ & -0.73 & 1.91 & 2.17 \\
$\mathrm{Fe}_{2} \mathrm{~N}$ & -0.40 & 1.70 & 2.18 \\
$\mathrm{Fe}_{3} \mathrm{~N}$ & -0.20 & 1.65 & 2.18 \\
$\mathrm{TiN}$ & -0.56 & 2.04 & 2.30 \\
\hline
\end{tabular}

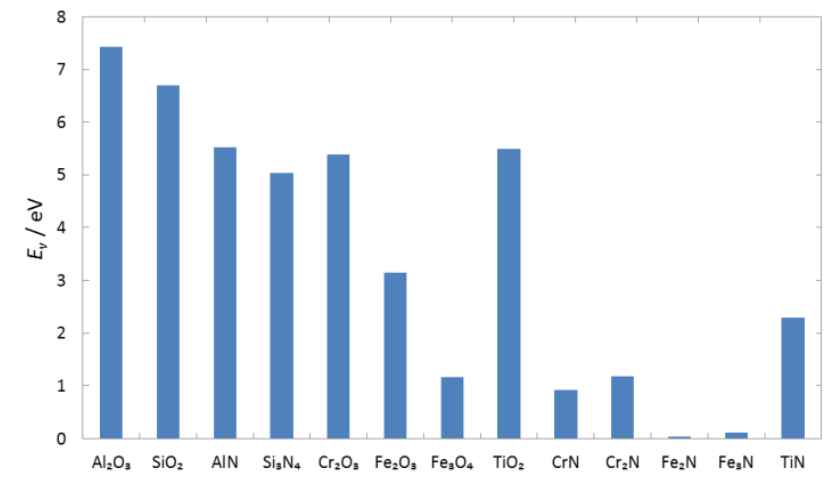

Figure 5. Calculated single anion vacancy formation energy.

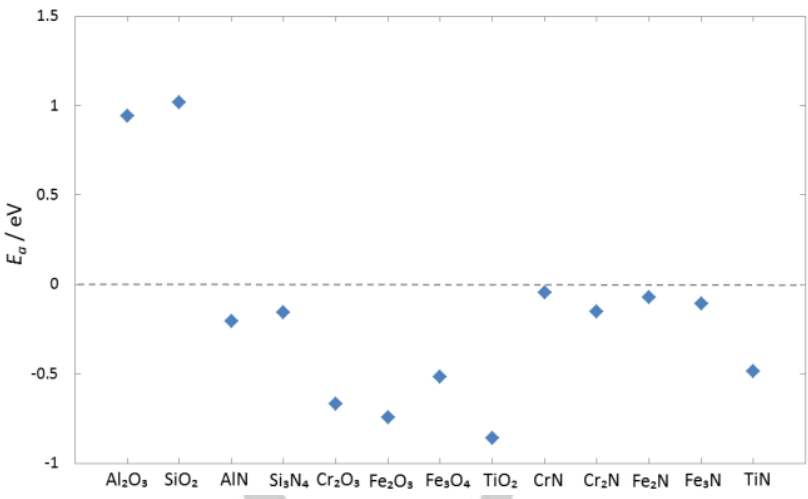

Figure 6. Calculated hydrogen absorption energy, including ZPE, in single anion-deficient ceramic materials.

Table 3. Oxidation number of $H$ atoms, the bond length of $H$ and corresponding atoms, and sum of corresponding ion radii ${ }^{[43]}$ in aniondeficient ceramic materials.

\begin{tabular}{cccc}
\hline & $\begin{array}{c}\text { Oxidation } \\
\text { number of } \mathrm{H} \\
\text { atoms }\end{array}$ & Bond length $(\AA)$ & $\begin{array}{c}\text { Sum of ion radii } \\
(\AA)\end{array}$ \\
\hline $\mathrm{Al}_{2} \mathrm{O}_{3}$ & -1.67 & 2.02 & 2.08 \\
$\mathrm{AIN}$ & -2.88 & 1.83 & 2.05 \\
$\mathrm{Si}_{3} \mathrm{~N}_{4}$ & -0.46 & 1.84 & 1.97 \\
$\mathrm{Cr}_{2} \mathrm{O}_{3}$ & -0.62 & 2.04 & 2.15 \\
$\mathrm{Fe}_{3} \mathrm{O}_{4}$ & -0.53 & 2.14 & 2.18 \\
$\mathrm{TiO}_{2}$ & -0.68 & 2.08 & 2.15 \\
$\mathrm{CrN}_{\mathrm{CrN}}$ & -0.69 & 2.13 & 2.16 \\
$\mathrm{Cr}_{2} \mathrm{~N}$ & -1.16 & 1.85 & 2.17 \\
$\mathrm{Fe}_{2} \mathrm{~N}$ & -0.51 & 1.89 & 2.18 \\
$\mathrm{Fe}_{3} \mathrm{~N}$ & -0.54 & 1.90 & 2.18 \\
$\mathrm{TiN}$ & -1.10 & 2.20 & 2.30 \\
\hline
\end{tabular}

shown in Figures $\mathrm{S} 6$ and $\mathrm{S} 7$, it is found that the $\mathrm{H}$ atoms do not form covalent bonds with coordinated atoms, except for $\mathrm{SiO}_{2}$ and $\mathrm{Fe}_{2} \mathrm{O}_{3}$. Table 3 shows the corresponding oxidation numbers of the $\mathrm{H}$ atoms in the anion-deficient ceramic materials, which indicates that $\mathrm{H}$ atoms in such materials are negatively charged because of the existence of excess electrons. In addition, anion vacancy sites are coordinated with cations. Consequently, $\mathrm{H}$ atoms can favorably absorb in anion-deficient ceramic materials via attractive Coulombic interactions. In contrast, from Figure $\mathrm{S6}$ (b), we can see the covalent bond is formed between $\mathrm{H}$ and $\mathrm{Si}$ atoms. In the case of anion-deficient $\mathrm{Fe}_{2} \mathrm{O}_{3}, \mathrm{H}$ atoms form hydroxyl groups, just as in the pristine case. $\mathrm{Fe}_{2} \mathrm{O}_{3}$ with a single vacancy forms a $\mathrm{Fe}_{3} \mathrm{O}_{4}$-like local atomic configuration. Then, the $\mathrm{H}$ atoms can approach toward the $\mathrm{O}$ atoms and an absorbed hydrogen isotope forms a hydroxyl group. $\mathrm{Al}_{2} \mathrm{O}_{3}$ and $\mathrm{Cr}_{2} \mathrm{O}_{3}$ also have the same local atomic structure. However, $\mathrm{Al}$ atoms are a main-group element and $\mathrm{Cr}$ atoms are more easily oxidized than Fe atoms. ${ }^{[44]}$ Therefore, these elements do not prefer excess electrons and form $\mathrm{H}^{-}$to release the excess electrons induced by $\mathrm{O}$ vacancy formation. We note that in comparison with the hydrogen absorption energy with and without anion vacancy, $\mathrm{H}$ 


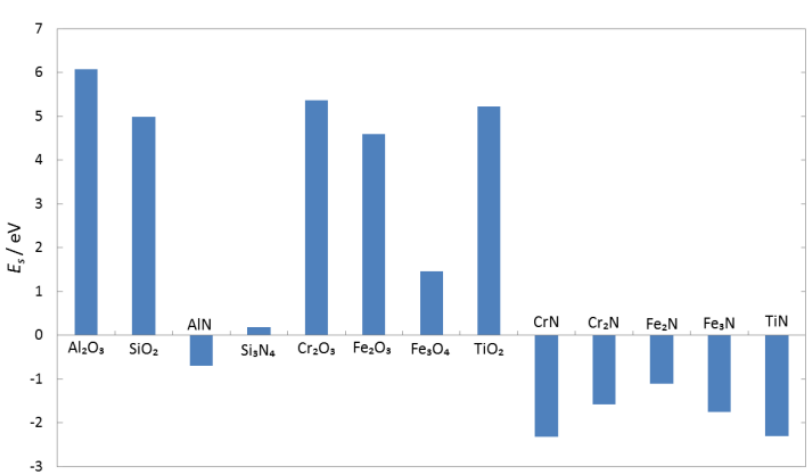

Figure 7. Calculated single anion substitution energy.

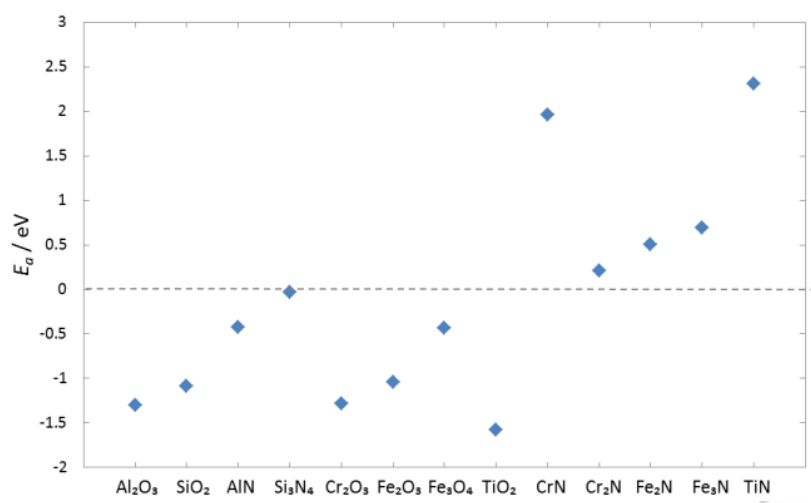

Figure 8. Calculated hydrogen absorption energy, including ZPE, in single anion-substituted ceramic materials.

atoms absorb more favorably in pristine $\mathrm{Fe}_{3} \mathrm{O}_{4}$, where $\mathrm{H}$ atoms are absorbed at interstitial sites, than in anion-deficient $\mathrm{Fe}_{3} \mathrm{O}_{4}$. This is because the covalent bonds between the $\mathrm{O}$ and $\mathrm{H}$ atoms are more stable than the ionic bonds in $\mathrm{Fe}_{3} \mathrm{O}_{4}$. Therefore, the most stable absorption sites in anion-deficient $\mathrm{Fe}_{3} \mathrm{O}_{4}$ are still interstitial sites.

\section{Hydrogen absorption in ceramic materials with a single anion-substitutional impurity}

Figure 7 shows the anion substitutional energies, $E_{S}^{N}$ and $E_{S}^{O} . E_{S}^{N}$ shows a large positive value, while $E_{S}^{O}$ shows a smaller or negative value. This is because in the gas phase $\mathrm{N}_{2}$ is more stable than $\mathrm{O}_{2}$, and the oxide phase of the cations considered in this study is more stable than the nitride phase, which means that the cations prefer to bond with $\mathrm{O}$ atoms than with $\mathrm{N}$ atoms. In the case of $\mathrm{N}$ substitutional doping into oxides, the substituted $\mathrm{N}$ atom has an oxidation number of -2 , while the stable closedshell states of $\mathrm{N}$ anions have an oxidation number of -3 . However, O substitutional doping into the nitrides introduces excess electrons. As mentioned vide supra, main-group elements become unstable with electron-excess and deficiency, which results in difficult anion substitution. We note that the transition metal oxides with high oxidation states become unstable through the deficiency of electrons induced by $\mathrm{N}$

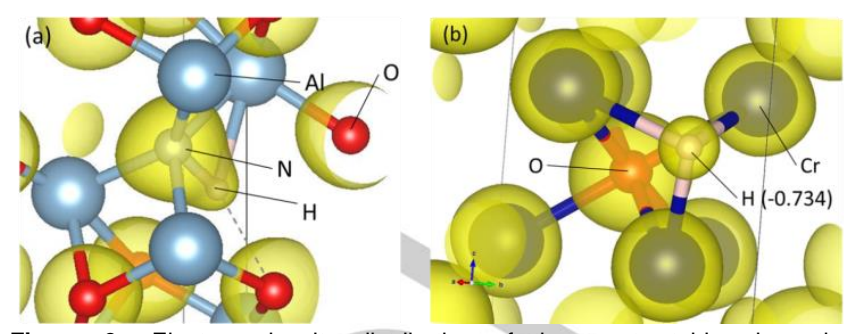

Figure 9. Electron density distribution of the most stable absorption configuration of (a) $\mathrm{Al}_{2} \mathrm{O}_{3}$ and (b) $\mathrm{Cr}_{2} \mathrm{~N}$ with single substitutional impurity. The isosurface is described at $0.7 \mathrm{e} / \AA^{3}$.

Table 4. Oxidation number of $\mathrm{H}$ atoms, the bond length of $\mathrm{H}$ and corresponding atoms, and sum of corresponding ion radii ${ }^{[43]}$ in anionsubstituted ceramic materials.

\begin{tabular}{cccc}
\hline & $\begin{array}{c}\text { Oxidation } \\
\text { number of } \mathbf{H} \\
\text { atoms }\end{array}$ & $\begin{array}{c}\text { Bond length } \\
(\AA)\end{array}$ & $\begin{array}{c}\text { Sum of ion } \\
\text { radii }(\AA)\end{array}$ \\
\hline AIN & -1.10 & 1.82 & 2.05 \\
$\mathrm{Cr}_{2} \mathbf{N}$ & -0.66 & 1.70 & 2.17 \\
$\mathrm{Fe}_{2} \mathbf{N}$ & -0.38 & 1.65 & 2.18 \\
$\mathrm{Fe}_{3} \mathbf{N}$ & -0.48 & 2.02 & 2.18 \\
$\mathrm{TiN}$ & -0.60 & 1.73 & 2.30 \\
\hline
\end{tabular}

substitutional doping because of the large ionization energy of the transition metal cations.

From Figure 8 , it is found that the hydrogen atoms can absorb more favorably in the anion-substituted ceramic materials, except for transition metal nitrides, than the pristine cases. In the cases of transition metal nitrides, the effects of the anion substitutional impurities are smaller than those of the other cases, especially the adsorption energies of $\mathrm{CrN}$ and $\mathrm{TiN}$, which are still positive. Figure 9(a) shows the electron density distributions in the vicinity of a hydrogen atom in $\mathrm{N}$-substituted $\mathrm{Al}_{2} \mathrm{O}_{3}$. There is an increased localization of electrons between the $\mathrm{H}$ and $\mathrm{N}$ atoms, which indicates a covalent bond between them. Figure S8 shows the differential electron density distribution of before versus after $\mathrm{H}$ absorption in the anionsubstituted oxides. We find increased localization of electrons between the $\mathrm{H}$ and $\mathrm{N}$ atoms in all of the $\mathrm{N}$-substituted oxides, which indicates that a covalent bond is formed between $\mathrm{H}$ and the electron-deficient $\mathrm{N}$ atoms. In contrast, in the case of nitrides, a hydrogen atom obtains the excess electrons and is negatively charged except for $\mathrm{Si}_{3} \mathrm{~N}_{4}$ and $\mathrm{CrN}$, as shown in Figures $9(\mathrm{~b})$ and S9. In the cases of $\mathrm{Si}_{3} \mathrm{~N}_{4}$ and $\mathrm{CrN}, \mathrm{H}$ atoms form covalent bonds with $\mathrm{Si}$ and $\mathrm{N}$ atoms, respectively. In the case of $\mathrm{Si}_{3} \mathrm{~N}_{4}$, as we mentioned, hydrogen atoms are coordinated with $\mathrm{N}^{3-}$, which results in no ionic bond with ceramic materials. Table 4 shows the oxidation number of the $\mathrm{H}$ atoms and the bond length between $\mathrm{H}$ and the coordinated cations in O-substituted nitrides. We note that the electron density in the vicinity of a hydrogen atom also increases in O-substituted AIN (see Figure S9), but the Bader charge analysis cannot calculate the oxidation number accurately. These indicate that $\mathrm{H}$ atoms become hydride ion-like states. In addition, the bond distance between $\mathrm{H}$ and the coordinated cations almost corresponds to the sum of the ionic 
radii of anions and $\mathrm{H}^{-}$. Therefore, the $\mathrm{H}$ atom forms an ionic bond with the coordinated cationic ions.

Finally, we explore the promise of the materials as HPBs based on two factors: (1) A positive hydrogen absorption energy, and (2) a positive defect formation energy. First, pristine $\mathrm{Al}_{2} \mathrm{O}_{3}$ and $\mathrm{SiO}_{2}$ show large positive hydrogen absorption energies. The anion-defective $\mathrm{Al}_{2} \mathrm{O}_{3}$ and $\mathrm{SiO}_{2}$ absorb hydrogen more favorably, but the corresponding defect formation energy is greater than 6 $\mathrm{eV}$. Therefore, it can be concluded that $\mathrm{Al}_{2} \mathrm{O}_{3}$ and $\mathrm{SiO}_{2}$ are promising materials for HPBs. The pristine and O-substituted $\mathrm{CrN}$ and $\mathrm{TiN}$ show positive hydrogen absorption energies. The $\mathrm{N}$-deficient $\mathrm{CrN}$ and TiN absorb hydrogen more favorably, but the corresponding $\mathrm{N}$ vacancy formation energy is greater than $1.5 \mathrm{eV}$. Thus, $\mathrm{CrN}$ and $\mathrm{TiN}$ are also promising materials for HPBs. The other ceramic materials studied cannot satisfy these properties.

\section{Isotope effect on hydrogen absorption states in ceramic materials}

Table 5 shows the isotope effect on hydrogen absorption energy in ceramic materials. In the present definition of absorption energy which include the ZPE of hydrogen isotope diatomic molecules, the trends of isotope effects depend on the sign of ZPE deference between before and after absorption, as shown in Figure S10. From Table 5, in the cases of pristine ceramic materials, it was found that the same isotope effects are evident in almost all ceramics, except $\mathrm{Si}_{3} \mathrm{~N}_{4}$ and $\mathrm{Fe}_{2} \mathrm{~N}$, i.e. heavier isotopes absorb more favorably than lighter ones. This means that the ZPE of hydrogen isotopes in ceramic materials is greater than those of hydrogen isotope atoms in corresponding diatomic molecules. Specifically, in the cases of the transition metal oxides, the isotope effects are greater than those of the others. This is because strong $\mathrm{OH}$ bonds are formed, which results in the strong confinement of hydrogen isotope atoms. However, $\mathrm{Si}_{3} \mathrm{~N}_{4}$ and $\mathrm{Fe}_{2} \mathrm{~N}$ show very small value of isotope effect, and it means that the bonds of hydrogen atoms in these materials are very weak. In the cases of anion-deficient ceramic materials, confinement of hydrogen isotopes becomes weaker than in the pristine cases. Therefore, the isotope dependence of the hydrogen absorption energy becomes smaller. On the other hand, ZPE is greater in the anion-substituted ceramic materials than in the corresponding pristine ceramic materials. The origins of the large ZPE are the similar spatial confinements and the stronger chemical bonding than those in the pristine cases. We note that the calculated adsorption energy difference of hydrogen isotopes in all ceramic materials is less than $0.18 \mathrm{eV}$, and ZPE does not affect the relatively stability of the absorption sites.

We also consider the free hydrogen isotope atoms as the origin of the absorption energy, which is a simple model for the nuclear fusion reactor condition. The calculated hydrogen absorption energy in pristine, anion-deficient, and anionsubstituted ceramic materials are shown in Figure S11, S12, and $\mathrm{S} 13$, respectively. We can find that the pristine $\mathrm{Al}_{2} \mathrm{O}_{3}$ and $\mathrm{SiO}_{2}$ have positive hydrogen absorption energy. Although the isotope effects become more pronounced as shown in Table S3
Table 5. The isotope effect on hydrogen absorption energy in ceramic materials.

\begin{tabular}{|c|c|c|c|c|}
\hline & & \multicolumn{3}{|c|}{ Adsorption energy difference from $\mathrm{H}(\mathrm{eV})$} \\
\hline & & pristine & anionic vacancy & anionic substitution \\
\hline \multirow{2}{*}{$\mathrm{Al}_{2} \mathrm{O}_{3}$} & D & -0.01 & -0.05 & -0.11 \\
\hline & $\mathbf{T}$ & -0.02 & -0.07 & -0.16 \\
\hline \multirow{2}{*}{$\mathrm{SiO}_{2}$} & D & -0.03 & -0.04 & -0.12 \\
\hline & $\mathbf{T}$ & -0.04 & -0.06 & -0.18 \\
\hline \multirow{2}{*}{ AIN } & D & -0.02 & -0.05 & -0.10 \\
\hline & $\mathbf{T}$ & -0.03 & -0.08 & -0.14 \\
\hline \multirow{2}{*}{$\mathrm{Si}_{3} \mathrm{~N}_{4}$} & D & 0.04 & -0.06 & -0.07 \\
\hline & $\mathbf{T}$ & 0.05 & -0.09 & -0.10 \\
\hline \multirow{2}{*}{$\mathrm{Cr}_{2} \mathrm{O}_{3}$} & D & -0.10 & -0.02 & -0.10 \\
\hline & $\mathbf{T}$ & -0.14 & -0.02 & -0.14 \\
\hline \multirow{2}{*}{$\mathrm{Fe}_{2} \mathrm{O}_{3}$} & D & -0.10 & -0.10 & -0.10 \\
\hline & $\mathbf{T}$ & -0.15 & -0.14 & -0.14 \\
\hline \multirow{2}{*}{$\mathrm{Fe}_{3} \mathrm{O}_{4}$} & D & -0.09 & -0.01 & -0.08 \\
\hline & $\mathbf{T}$ & -0.13 & -0.01 & -0.12 \\
\hline \multirow{2}{*}{$\mathrm{TiO}_{2}$} & D & -0.09 & -0.04 & -0.10 \\
\hline & $\mathbf{T}$ & -0.13 & -0.05 & -0.14 \\
\hline \multirow{2}{*}{$\mathrm{CrN}$} & D & -0.04 & 0.00 & -0.05 \\
\hline & $\mathbf{T}$ & -0.06 & 0.00 & -0.07 \\
\hline \multirow{2}{*}{$\mathrm{Cr}_{2} \mathrm{~N}$} & D & -0.02 & -0.04 & -0.10 \\
\hline & $\mathbf{T}$ & -0.03 & -0.05 & -0.14 \\
\hline \multirow{2}{*}{$\mathrm{Fe}_{2} \mathrm{~N}$} & D & 0.01 & 0.00 & 0.00 \\
\hline & $\mathbf{T}$ & 0.02 & 0.00 & 0.00 \\
\hline \multirow{2}{*}{$\mathrm{Fe}_{3} \mathrm{~N}$} & D & -0.09 & 0.03 & -0.10 \\
\hline & $\mathbf{T}$ & -0.14 & 0.04 & -0.14 \\
\hline \multirow{2}{*}{$\mathrm{TiN}$} & D & -0.07 & -0.00 & -0.06 \\
\hline & $\mathbf{T}$ & -0.10 & -0.01 & -0.09 \\
\hline
\end{tabular}

because of the absence of ZPE in isolated hydrogen isotopes, the calculated isotope effects on absorption energy are still less than $0.30 \mathrm{eV}$. Therefore, the choice of hydrogen resource can be approximately treated by energy shift, and the former discussion about material screening can be applied to this condition. From these points, $\mathrm{Al}_{2} \mathrm{O}_{3}$ and $\mathrm{SiO}_{2}$ are promising deuterium and tritium permeation barriers.

\section{Conclusions}

The absorption states of hydrogen isotopes in ceramic materials were investigated by first-principles calculations based on spin-polarized DFT, including ZPE. In the case of pristine ceramic materials, the hydrogen absorption energy strongly depends on the cation in the ceramic material. Main-group oxides do not form any bond with a hydrogen atom. However, transition metal oxides form hydroxyl groups, and favorably absorb hydrogen atoms. Main-group and transition metal nitrides form ionic bonds between the hydrogen atom and surrounded cation. In the cases of anion-deficient ceramic materials, the hydrogen atoms are negatively charged because of excess 
electrons induced by anion vacancies, and these form ionic bonds with the surrounded cations, thus stabilizing the hydrogen absorption states. $\mathrm{N}$ substitutional doping into oxides introduces an electron hole, while $\mathrm{O}$ substitutional doping into the nitrides introduces an excess of electrons. Therefore, hydrogen isotopes form covalent bonds in $\mathrm{N}$-substituted oxides, and form hydride ions in O-substituted nitrides. Finally, the promise of the materials for HPB was explored based on two factors: (1) a positive hydrogen absorption energy, and (2) a positive defect formation energy. From these considerations, it can be concluded that $\mathrm{Al}_{2} \mathrm{O}_{3}, \mathrm{SiO}_{2}, \mathrm{CrN}$ and $\mathrm{TiN}$ are promising materials for HPBs. It is noted that the isotope effects on the absorption energies in all cases are in the order of $0.1 \mathrm{eV}$. Furthermore, it has been reported that the grain boundary may also enhance hydrogen permeation. ${ }^{[43,44]}$ Therefore, hydrogen permeation with the co-existence of anion defects and a grain boundary is an ongoing study.

\section{Acknowledgments}

This work was supported by MEXT KAKENHI: Grant-in-Aid for Young Scientists (B), No. 17K14114. This work used the facilities of the Supercomputer Center, the Institute for Solid State Physics, the University of Tokyo.

Keywords: Hydrogen absorption - Ceramics materials • Density functional theory $\bullet$ anionic defects $\bullet$ Hydrogen economy

[1] G. W. Crabtree, M. S. Dresselhaus, M. V. Buchanan, Phys. Today 2004, $57,39-45$

[2] N. Nakicenovic, M. Jefferson, Int. Inst. Appl. Syst. Anal. 2006, 1-14

[3] T. Omura, J. Nakamura, ISIJ Int. 2012, 52, 234-239

[4] G. W. Hollenberg, E. P. Simonen, G. Kalinin, A. Terlain, Fusion Eng. 1995, 28, 190-208

[5] D. Mori, K. Hirose, Int. J. Hydrogen Energy 2009, 34, 4569-4574

[6] H. Z. Wang, D. Y. C. Leung, M. K. H. Leung, M. Ni, Renew. Sustain. Energy Rev. 2009, 13, 845-853

[7] L. Barreto, A. Makihira, K. Riahi, Int. J. Hydrogen Energy 2003, 28, 267-284

[8] Q. Li, L.-B. Mo, J. Wang, K. Yan, T. Tang, Y.-C. Rao, W.-Q. Yao, J.-L. Cao, Int. J. Hydrogen Energy 2015, 40, 6459-6464

[9] D. Levchuk, H. Bolt, M. Döbeli, S. Eggenberger, B. Widrig, J. Ramm, Surf. Coatings Technol. 2008, 202, 5043-5047

[10] R. Checchetto, M. Bonelli, L. M. Gratton, A. Miotello, A. Sabbioni, L. Guzman, Y. Horino, G. Benamati, Surf. Coatings Technol. 1996, 83, 40-44

[11] K. Saito, J. Vac. Sci. Technol. A Vacuum, Surfaces, Film. 1995, 13, 556

[12] T. Wang, J. Pu, C. Bo, L. Jian, Fusion Eng. Des. 2010, 85, 1068-1072
[13] V. D. Borman, E. P. Gusev, Y. Y. Lebedinskii, V. I. Troyan, Phys. Rev Lett. 1991, 67, 2387-2390

[14] R. J. Dexter, S. B. Watelski, S. T. Picraux, Appl. Phys. Lett. 1973, 23, 455-457

[15] F. Wang, W. Lai, R. Li, B. He, and S. Li, Int. J. Hydrogen Energy, 2016, 41, 22214-22220

[16] F. Filippone, G. Mattioli, P. Alippi, and A. Amore Bonapasta, Phys. Rev. B, 2009 80, 245203-1-8

[17] Y. Ikeda, K. Saito, S. Tsukahara, S. Ichimura, K. Kokubun, M. Hirata Shinku, 1998, 41, 507-509

[18] J. Kniep, Y. S. Lin, Ind. Eng. Chem. Res. 2010, 49, 2768-2774

[19] J. M. Polfus, T. S. Bjørheim, T. Norby R. Haugsrud, Phys. Chem. Chem. Phys. 2012, 14, 11808

[20] Y. Iwazaki, Y. Gohda, S. Tsuneyuki, APL Mater. 2014, 2, 012103

[21] H. Iwahara, T. Esaka, H. Uchida, N. Maeda. Solid State Ion. 1981, 3/4, 359-363

[22] G. Kresse, J. Hafner, Phys. Rev. B 1993, 47, 558-561

[23] G. Kresse, J. Hafner, Phys. Rev. B 1994, 49, 14251-14269

[24] G. Kresse, J. Furthmüller, Comput. Mater. Sci. 1996, 6, 15-50

[25] G. Kresse, J. Furthmüller, Phys. Rev. B 1996, 54, 11169-11186

[26] P. E. Blöchl, Phys. Rev. B 1994, 50, 17953-17979

[27] G. Kresse, D. Joubert, Phys. Rev. B 1999, 59, 1758-1775

[28] Perdew, J. P., Burke, K. \& Ernzerhof, M. Phys. Rev. Lett. 1996, 77, 3865-3868

[29] S. L. Dudarev, G. A. Botton, S. Y. Savrasov, C. J. Humphreys, A. P. Sutton, Phys. Rev. B 1998, 57, 1505-1509

[30] L. Wang, T. Maxisch, G. Ceder, Phys. Rev. B 2006, 73, 1-6

[31] P. Liao, E. A. Carter, J. Mater. Chem. 2010, 20, 6703

[32] V. I. Anisimov, I. S. Elfimov, N. Hamada, K. Terakura, Phys. Rev. B 1996, 54, 4387-4390

[33] B. J. Morgan, G. W. Watson, Surf. Sci. 2007, 601, 5034-5041

[34] L. Zhou, F. Körmann, D. Holec, M. Bartosik, B. Grabowski, J. Neugebauer, P. H. Mayrhofer, Phys. Rev. B 2014, 90, 184102

[35] Y. J. Shi, Y. L. Du, G. Chen, Comput. Mater. Sci. 2013, 67, 341-345

[36] G. Wang, J. Phys. Chem. C 2016, 120, 18850-18857

[37] H. Allmaier, L. Chioncel, E. Arrigoni, Phys. Rev. B 2009, 79, 235126

[38] J. D. Pack, H. J. Monkhorst, Phys. Rev. B 1977, 16, 1748-1749

[39] R. F. W. Bader, Acc. Chem. Res. 1985, 18, 9-15

[40] W. Tang, E. Sanville, G. J. Henkelman, J. Phys. Condens. Matter 2009, 21,84204

[41] K. Momma, F. Izumi, J. Appl. Crystallogr. 2011, 44, 1272-1276

[42] U. Keil, P. Schreier, J. Inorg. Nucl. Chem. 1961, 17, 215-221

[43] R. D. Shannon Acta Cryst. A 1976, 32, 751-767

[44] L. S. Darken and R. W. Gurry Physical Chemistry of Metals, McGrawHill Book Company, New York, 1953, pp. 349

[45] C. Kura, Y. Kunisada, E. Tsuji, C. Zhu, Hi. Habazaki, S. Nagata, M. P. Müller, R. A. De Souza, Y. Aoki, Nat. Energy 2017, 2, 786-794

[46] C. Kura, S. Fujimoto, Y. Kunisada, D. Kowalski, E. Tsuji, C. Zhu, H. Habazaki, Y. Aoki, J. Mater. Chem. A 2018, 6, 2730-2741 
Entry for the Table of Contents (Please choose one layout) ARTICLE
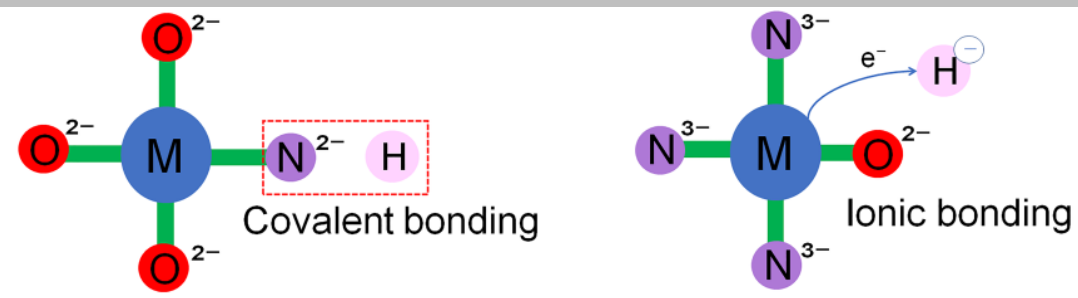

Takumi Watanabe, Yuji Kunisada, ${ }^{*}$ and Norihito Sakaguchi

Page No. - Page No.

Is hydrogen stable in unary ceramics?: The absorption states of hydrogen isotopes in various ceramic materials were investigated by density functional theory. We can systematically understand the chemical bonding between hydrogen and ceramic materials from the view point of deficient and excess electrons. In conclusion, we find that $\mathrm{Al}_{2} \mathrm{O}_{3}, \mathrm{SiO}_{2}, \mathrm{CrN}$, and $\mathrm{TiN}$ are promising materials as hydrogen permeation barriers. 